\title{
EVALUATION OF THE ROLE OF YKL-40 AND INTERLEUKIN-8 (IL-8) AS BIOMARKERS FOR MALIGNANT TRANSFORMATION IN ORAL LICHEN PLANUS
}

\author{
Eman M. Amr*, Amal A. Hussine ${ }^{* *}$, Rasha Wagih Mostafa** and Olfat G. Shaker***
}

\begin{abstract}
Objective: This investigation was conducted to measure the levels of serum and salivary YKL40 and IL-8 in patients suffering from OLP and OSCC to assess their potential role as biomarkers of oral cancer.

Methods: Forty five subjects with age ranging from 30 to 70 years were distributed into 3 groups; 15 patients having atrophic and/or erosive OLP, 15 patients suffering from OSCC and 15 systemically healthy control individuals.YKL-40 and IL-8 were identified in serum and saliva samples utilizing enzyme-linked immunosorbent assays.

Results: Serum YKL-40 and salivary levels of YKL-40 and IL-8 in patients with OSCC and OLP were significantly higher than the healthy control group. In order to differentiate patients having OLP from those suffering from OSCC, our study utilized the analysis of the receiver operating curve (ROC) which showed an AUC of $0.878,0.789,0.789$ and 0.7 for serum YKL-40, salivary YKL-40, serum IL-8, and salivary IL-8, respectively. Serum YKL-40 had the highest diagnostic accuracy revealing $93 \%$ sensitivity and $73 \%$ specificity. That has been followed by salivary YKL40 and serum IL-8, both revealing a good diagnostic accuracy with 93\%, 80 \% sensitivity, and $60 \%, 73.3 \%$ specificity respectively. Salivary IL- 8 as well yielded a good diagnostic accuracy and revealed degrees of sensitivity (80\%) and specificity (63\%). Cut off values of the biomarkers under investigation has been selected according to the distribution of sensitivities and specificities Conclusion: YKL-40 and IL-8 might be counted as biomarkers for identifying cancerous changes of OLP and the initial stage of OSCC.
\end{abstract}

KEY WORDS: Oral lichen planus, Oral squamous cell carcinoma, YKL-40, IL-8. Serum, Saliva.

* Associate Professor of Oral Medicine and Periodontology, Faculty of Dentistry, Cairo University.

** Lecturer of Oral Medicine and Periodontology, Faculty of Dentistry, Cairo University.

*** Professor of Biochemistry, Biochemistry Department, Faculty of Medicine, Cairo University. 


\section{INTRODUCTION}

Oral lichen planus (OLP) is considered to be one of the autoimmune disorders which appears in several different clinical forms that occur separately or simultaneously in the form of plaque-like, reticular, bullous, erosive and atrophic lesions. ${ }^{1}$

The possibility of cancerous changes in OLP is a debatable issue and is yet a matter of dispute in the current literature. OLP is counted as a premalignant condition according to the World Health Organization (WHO) and having a risk of malignant changes varying between $0 \%$ and $10 \%{ }^{2}$ Previous observations showed that regarding malignant transformation, there is no gender predilection with greater occurrence in individuals exceeding 40 years and most commonly occurring in the erosive type. ${ }^{3}$

The most common of all malignancies of the head and neck is that affecting the oral cavity, with oral squamous cell carcinoma (OSCC) being by far the mostly frequent single entity and highly aggressive malignancies worldwide, accounting alone for about $90 \%$ of all oral cancers. ${ }^{4}$

A scientific report strongly suggested that inflammation remains a crucial cause of specific malignancies of the epithelium. ${ }^{5}$ Increased conversion of normal cells to pre-neoplastic centers is associated with unresolved chronic inflammation which subsequently promotes cancer development. ${ }^{6}$ These inflammatory injuries lead to the upregulation of inflammatory mediators like tumor necrosis factor $\alpha$ (TNF $\alpha$ ), interferon $\alpha$ (IFN $\alpha$ ), IL $-1 \alpha / \beta$ and IL- $6,{ }^{7}$ which consequently promotes the expression of pro-inflammatory chemokines. ${ }^{8}$

One of the known pro-inflammatory chemokines is IL-8 which is released by a range of various cell types as neutrophils, lymphocytes, endothelial cells, epithelial cells, fibroblasts, monocytes, macrophages, as well as numerous cancer cells.., 10
IL-8 is a significant moderator of host reaction to inflammation and trauma, ${ }^{11}$ and takes part in the stimulation and attraction of neutrophils to the location of insult or infection. ${ }^{12}$ Moreover, it attracts $\mathrm{T}$ cells, natural killer cells, eosinophils and basophils. ${ }^{13}$. Therefore, IL-8 is considered to play an essential part in the natural immunity offering a primary line of resistance to attacking pathogens. ${ }^{14}$

Healthy tissues have insignificant amounts of IL-8 but its concentration quickly reaches 10-100 times its baseline level in reaction to pro-inflammatory cytokines like TNF- $\alpha$ or IL $-1 \beta$, bacteria or viruses, and cellular stress. ${ }^{15}$ Keratinocytes in OLP patients can synthesize IL-1 and TNF- $\alpha .{ }^{16}$ Moreover, mononuclear cells in the peripheral blood as well as those infiltrated in the tissues in mucosal OLP patients, can produce TNF- $\alpha .{ }^{17}$ Furthermore, following an increase in releasing of both IL-1 and TNF- $\alpha$ locally and systemically, macrophages, keratinocytes, endothelial cells, fibroblasts and T-cells in OLP lesions release significant amounts of IL-8, which leads to greater infiltration of T-cells such as cytotoxic T-cells locally in OLP. In addition, previous studies revealed that serum levels of IL8 and IL- 6 are greater in subjects having OLP in comparison to healthy individuals, ${ }^{18,19}$ and that serum level of IL-8 is a more specific indicator of OLP than IL-6. This suggests that IL- 8 could contribute to the pathologic process of OLP. ${ }^{18}$

Elevated amounts of IL-8 might augment carcinogenesis by promoting DNA damage and proliferation of cells as well as by up-regulating the action of collagenase type IV and matrix metalloproteinase -2 (MMP -2$).{ }^{20}$ Enhanced collagenase activity promotes invasion of cancer cells, increased angiogenesis and subsequently metastasis. Moreover, the use of synthesized positive inotropic agent (vesnarinone) lead to the down regulation of IL-8 expression which consequently inhibited both angiogenesis and tumorigenicity of OSCC cells. ${ }^{21}$ 
YKL- 40, also named Chitinase -3- like -1 $(\mathrm{CHI} 3 \mathrm{~L} 1)^{22}$ is a secreted glycoprotein, encoded by chitinase-3-like 1 protein..$^{23}$ Several types of cells as endothelial cells, cartilage, inflammatory cells, and cancer cells secrete YKL- $40 .{ }^{24}$ While the precise role of YKL-40 is unidentified, it has remained linked to several inflammatory and immune diseases in addition to numerous malignancies. ${ }^{25,26}$

The amounts of YKL-40 are raised during inflammation, considering that it plays a significant part in chemotaxis and in the activation and recruitment of inflammatory cells, as it takes part in the process of differentiation, proliferation and apoptosis of cells, angiogenesis, and extracellular matrix remodeling. ${ }^{25,26}$

Poor prognosis of a variety of medical, inflammatory and tumor processes are related to the increased amounts of YKL-40 in serum. ${ }^{27,} 28$ Moreover, YKL-40 is considered to be one of the pro-inflammatory agents and has been described to promote the induction of chemokines as IL- 8 from cancer cells..$^{29,30}$

Accordingly; this investigation was conducted to measure the levels of serum and salivary YKL- 40 and IL- 8 in patients suffering from OLP and OSCC to assess their potential role as biomarkers of oral cancer.

\section{SUBJECTS AND METHODS}

Forty five subjects with age ranging from 30 to 70 years were admitted in this investigation. They were enrolled from the outpatients' clinic of Oral medicine and Periodontology department, Faculty of Dentistry, Cairo University. Subjects were distributed into 3 groups: 15 patients having atrophic and/or erosive OLP, 15 patients suffering from OSCC and 15 systemically healthy control individuals. For each individual, a thorough medical history was acquired based on the modified Cornell Medical Index's questionnaire. ${ }^{31}$ An informed consent was signed by all participants once the nature of the investigation has been clarified.
Diagnosis of patients with OLP as well as OSCC was done clinically and biopsy specimens were obtained from the lesions to confirm the diagnosis histopathologically.

\section{Collection of saliva samples:}

Before any treatment and from all subjects, complete unstimulated saliva was assembled. For not less than one 60 minutes prior to sampling, all participants were requested to abstain from drinking, eating, or consuming chewing gum. Samples were acquired by requesting from the patient to swallow at first, incline the head frontward, and for 5 minutes, in the absence of swallowing, spit the whole saliva within 50-ml sterile centrifuge tubes. Once assembled, all specimens were directly kept at $-20^{\circ} \mathrm{C}$ until analyzed.

\section{Serum sampling:}

From each individual, $2 \mathrm{ml}$ of venous blood samples were drained by regular venipuncture. In sterile tubes containing 15\% K3EDTA solution, all blood sample were collected.

\section{Detection of serum and salivary IL-8 samples:}

Amounts of IL-8 were estimated in all salivary and serum samples by using an ELIZA kit (Orgenium laboratories, business unit, Finland). A sandwich-type ELIZA was adopted where a polyclonal anti-IL-8 antibody, adsorbed onto micro wells, binds IL- 8 in the specimen. This assay utilize a human IL-8 specific antibody treated on a 96 -well plate. Within the wells, samples, standards, and biotinylated anti-human IL- 8 are pipetted and any IL- 8 existing is bound via the immobilized antibody. HRP-conjugated streptavidin is pipetted into the wells once unbound biotinylated antibody is washed away. Again the wells are washed. A color comparative to the quantity of bound IL- 8 develops after adding to the wells the TMB substrate solution. The color changes from blue to yellow by the Stop solution. Using ELIZA reader, the strength of the color is evaluated at $450 \mathrm{~nm}$. 


\section{Evaluation of YKL-40 in serum and saliva:}

Utilizing ELISA kit presented by Quantikine R \& D systems, Minneapolis, USA ( Catalog Number DC3L10), quantitation of Human YKL40 in saliva and serum samples was performed. The quantitative sandwich enzyme immunoassay method was employed. Pre-coated onto a microplate, a monoclonal YKL-40 specific antibody has been used. After pipetting the samples and standards within the wells, any YKL- 40 existing is held via the immobilized antibody. Once washed, an enzyme-linked polyclonal YKL-40 specific antibody is put into the wells. After adding to the wells a substrate solution, color appears proportional to the quantity of YKL- 40 secured in the first stage. The concentration of the color is measured from the standard curve at $450 \mathrm{~nm}$ using ELISA reader.

\section{Statistical analysis}

Quantitative data were demonstrated as median, mean, standard deviation (SD), range (Minimum - Maximum) and 95\% confidence interval (95\% CI) for the mean values. By inspecting the data distribution and by means of Kolmogorov-Smirnov and Shapiro-Wilk tests, data were investigated for normality. Age data revealed normal (parametric) distribution, while the data for YKL-40 and IL-8 revealed non-normal (non-parametric) distribution.

For parametric data; one- way ANOVA test was utilized to compare between the three groups. Whereas, Kruskal-Wallis test was utilized to compare between the three groups for nonparametric data. When Kruskal- Wallis test is significant, Dunn's test was applied for pair-wise comparisons. Qualitative data were demonstrated as frequencies and percentages. To compare between the three groups Fisher's Exact test was adopted. The significance level was set at $\mathrm{P} \leq 0.05$.

A receiver operating characteristic (ROC) curve study was executed to evaluate the diagnostic efficacy of the biomarkers under study. A straight estimate of the diagnostic accuracy of the tested biomarkers was offered by the area under the curve (AUC). The biological marker which revealed the biggest AUC has been recognized as manifesting the greatest diagnostic accuracy for distinguishing OLP from OSCC. The value with the greatest sensitivity and specificity and which existed nearest to the upper left side of the curve determines the best cut off point for each biomarker. IBM ${ }^{\circledR}$ SPSS $®$ Statistics Version 20 for Windows was utilized to perform the statistical analysis.

\section{RESULTS}

In serum, OSCC group revealed the statistically significant highest mean YKL-40 level. OLP group showed a significantly lower mean value. The control group revealed the statistically significantly lowest mean YKL-40 levels. A significant difference between OSCC group and OLP group also between each of the study groups and the control group was shown.

Similarly, in saliva, OSCC group also yielded the statistically significantly highest mean YKL40 level. OLP group showed a lower mean value followed by the control group showing the lowest mean value. No significant difference between OSCC and OLP groups was detected, yet upon comparing both the OSCC group and the OLP group to the healthy controls, a significant difference was shown.

As regards IL-8, in serum, a statistically significant difference among OSCC group and the control group was shown being highest in the OSCC group. Whereas, between OSCC and OLP or between OLP and control, no significant difference was detected.

In saliva, no significant difference was shown comparing OSCC group to OLP group; both

\footnotetext{
${ }^{\circledR}$ IBM Corporation, NY, USA.

${ }^{\circledR}$ SPSS, Inc., an IBM Company.
} 
revealed the significantly highest mean levels of IL8. Meanwhile, the statistically significantly lowest mean IL-8 level was shown by control group.

A ROC curve analysis was conducted to distinguish the studied biomarkers for the initial prediction of OSCC. For identifying the initial stage of OSCC, cut off values of the biomarkers under investigation has been selected according to the distribution of sensitivities and specificities.

In order to differentiate patients having OLP from those suffering from OSCC, analysis of the ROC curve showed an AUC of 0.878, 0.789, 0.789 and 0.7 for serum YKL-40, salivary YKL-40, serum IL-8, and salivary IL-8, respectively, (Fig.1). Serum YKL-40 had the highest diagnostic accuracy (AUC 0.878 ), where a cutoff point of $>1771.9 \mathrm{ng} / \mathrm{ml}$ has been identified revealing $93 \%$ sensitivity and 73 $\%$ specificity. That has been followed by salivary YKL-40 and serum IL-8, both revealing a good diagnostic accuracy (AUC 0.789), with 93\%, $80 \%$ sensitivity, and $60 \%, 73.3 \%$ specificity respectively with a cut off values of $>1095.575$ and $>9.32 \mathrm{pg} / \mathrm{ml}$ respectively. Salivary IL- 8 as well yielded a good diagnostic accuracy (AUC 0.7 ) with a cut-off point of $>2980 \mathrm{pg} / \mathrm{ml}$ and revealed degrees of sensitivity $(80 \%)$ and specificity (63\%). The subjects exceeding such cut off measures has been regarded as cancerous and beneath such cut off points has been regarded as patients having OLP alone.

Table 3 shows the cut-off points, corresponding sensitivities and specificities as well as the AUC for the biomarkers under study in diagnosing OSCC, OLP and differentiating between them.

TABLE (1) Descriptive statistics and results of Kruskal-Wallis test for comparison between YKL-40 levels $(\mathrm{ng} / \mathrm{ml})$ in the three groups

\begin{tabular}{|c|c|c|c|c|c|c|c|c|c|}
\hline & \multirow{2}{*}{ Group } & \multirow{2}{*}{ Mean } & \multirow{2}{*}{ SD } & \multirow{2}{*}{ Median } & \multirow{2}{*}{ Minimum } & \multirow{2}{*}{ Maximum } & \multicolumn{2}{|c|}{$95 \%$ CI } & \multirow{2}{*}{$P$-value } \\
\hline & & & & & & & Lower bound & Upper bound & \\
\hline \multirow{3}{*}{ Serum } & OSCC & $5141.8^{\mathrm{a}}$ & 4990.7 & 4399.1 & 1272.6 & 22534.0 & 2378.1 & 7905.6 & \multirow{3}{*}{$<0.001 *$} \\
\hline & LP & $2602.7^{b}$ & 1640.3 & 2094.6 & 769.2 & 4989.4 & 1694.3 & 3511.0 & \\
\hline & Control & $965.5^{\mathrm{c}}$ & 237.0 & 924.8 & 555.8 & 1551.2 & 974.6 & 1096.8 & \\
\hline \multirow{3}{*}{ Saliva } & OSCC & $1718.0^{\mathrm{a}}$ & 1170.5 & 1237.5 & 1012.2 & 5678.0 & 1069.8 & 2366.2 & \multirow{3}{*}{$<0.001 *$} \\
\hline & LP & $1107.6^{\mathrm{a}}$ & 240.1 & 1219.5 & 561.8 & 1310.4 & 466.8 & 1240.6 & \\
\hline & Control & $752.2^{b}$ & 296.3 & 723.1 & 211.8 & 1239.7 & 588.1 & 916.4 & \\
\hline
\end{tabular}

*: Significant at $P \leq 0.05$, dissimilar letters in the same column indicate statistically significant difference

TABLE (2): Descriptive statistics and results of Kruskal-Wallis test for comparison between IL-8 levels (pg/ $\mathrm{ml})$ in the three groups

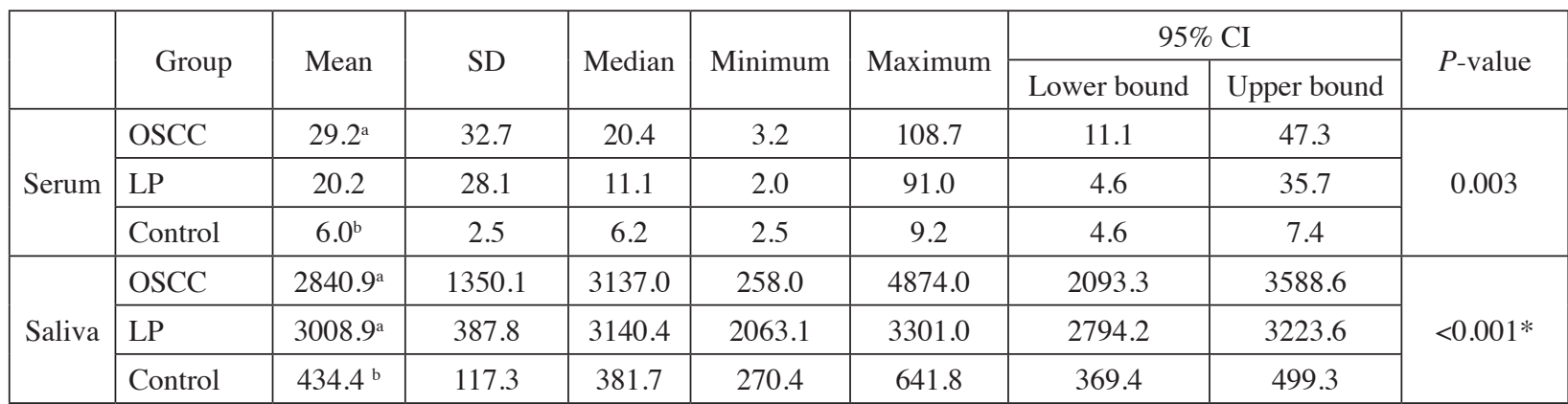

*: Significant at $P \leq 0.05$, dissimilar letters in the same column indicate statistically significant difference 


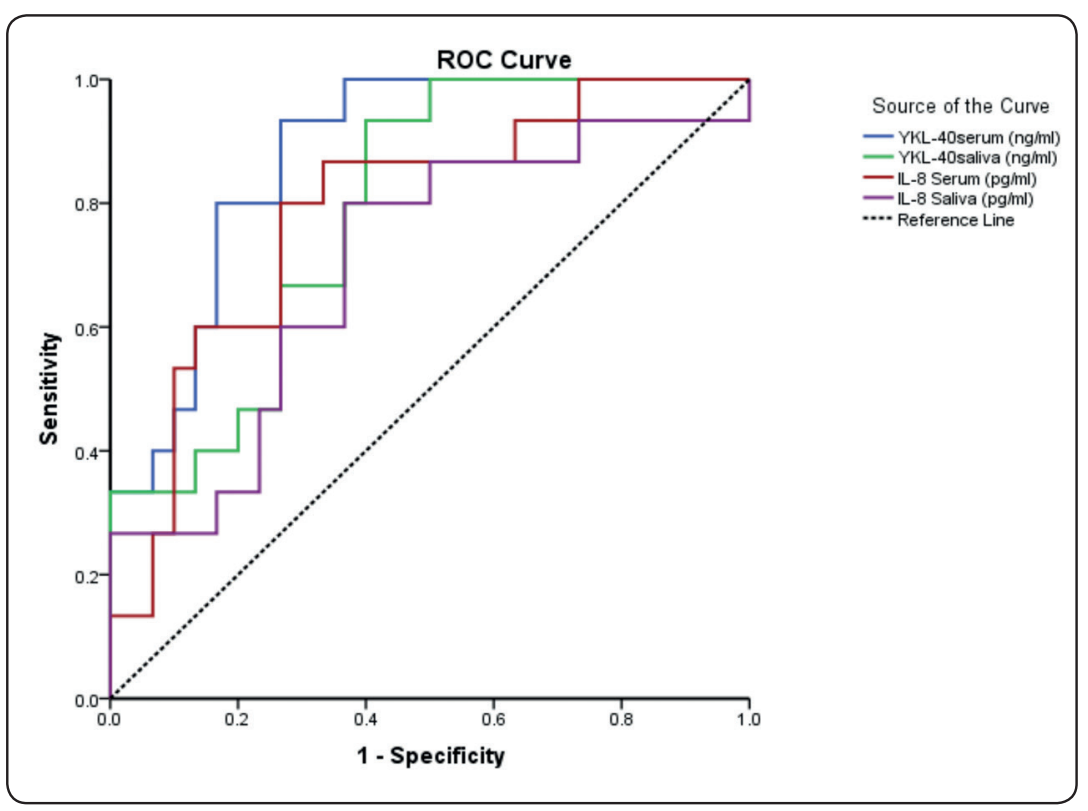

Fig.1: ROC curve for YKL-40 and IL-8 in serum and saliva for distinguishing OSCC from OLP.

Table 3: ROC curve interpretation of YKL-40 and IL- 8 biomarkers in serum and saliva for differentiating OSCC from OLP.

\begin{tabular}{|c|c|c|c|c|c|c|}
\hline Biomarker & Cut off point & Sensitivity \% & Specificity \% & $\begin{array}{c}\text { AUC } \\
(95 \% \mathrm{CI})\end{array}$ & SE value \\
\hline Serum YKL-40 (ng/ml) & 1771.9 & 93.3 & 73.3 & $\begin{array}{c}0.878 \\
(0.78-0.975)\end{array}$ & 0.05 & $<0.001$ \\
\hline $\begin{array}{c}\text { Salivary YKL-40 (ng/ } \\
\mathrm{ml})\end{array}$ & 1095.575 & 93.3 & 60 & $\begin{array}{c}0.789 \\
(0.658-0.92)\end{array}$ & 0.067 & 0.002 \\
\hline $\begin{array}{c}\text { Serum IL-8 (pg/ml) } \\
\text { Salivary IL-8 (pg/ml) }\end{array}$ & 9.32 & 80 & 73.3 & 0.789 & 0.071 & 0.002 \\
& 80 & 63.3 & $\begin{array}{c}0.649-0.929) \\
(0.532-0.868)\end{array}$ & 0.086 & 0.03 \\
\hline
\end{tabular}

\section{DISCUSSION}

Currently, OSCC is detected based on detailed clinical examination joined with laboratory investigation through biopsy acquisition for histological testing. Unfortunately, most of the cases of OSCC are not identified except after an advanced stage of the cancer has been reached; thus, early cancer detection using a reliable diagnostic marker is needed to reach the best prognosis and also raise the possibility of treatment. ${ }^{32,33}$ Based on the current literature, the authors' claim that this is the primary investigation that aims to study the level of YKL-40 in the saliva of patients with OSCC and OLP. In this study, YKL-40 in serum and saliva was significantly higher in patients suffering from OSCC and OLP as compared to healthy individuals being highest in OSCC group. Also, IL-8 in serum and saliva was significantly higher in OSCC and OLP groups when compared to the healthy individuals.

It has been indicated that chronic inflammation 
supports cell proliferation, differentiation, survival and growth, through the production of different cytokines. This can promote initiation and progression of cancer. ${ }^{34}$ Accordingly, several trials have been adopted to recognize patients with OLP who were at risk of malignant transformation and it has been recommended that these patients should be cautiously followed and accurate diagnosis should be reached as early as possible. ${ }^{35}$

Several studies demonstrated an increase in NFkB dependent cytokines, IL-6, TNF- $\alpha$, IL- $1 \alpha$ and I L-8 in the various fluids of the oral cavity, ${ }^{36}$ serum, oral epithelial cells as well as tissue infiltrated mononuclear cells of OLP. ${ }^{37}$ Those investigations emphasize the probability that the NF-kB and its dependent cytokines create an inflammatory microenvironment which favors the beginning and/ or progression of the cancerous alteration of OLP. The change in the expression level of proteins associated with cell proliferation rate and apoptosis can be utilized as a predictor for the increased possibility of malignant development. ${ }^{2}$

Waugh and Wilson ${ }^{9}$ proposed that within the tumor microenvironment, IL-8 might act as an important modulating agent as its elevated expression has been represented in malignant cells and cancer associated macrophages. Additionally, Rao et al..$^{38}$ confirmed that IL- 8 activates other genes associated with cancer development such as that of vascular endothelial growth factor (VEGF), suggesting that it can contribute to cancer. It has also been reported to take part in tumor-derived angiogenic activity in various human cancers ${ }^{39,40}$. Such findings intensely propose that IL-8 plays a role as a significant regulator in OSCC.

In the present study, and in all the included groups, salivary IL- 8 levels were greater than that in the serum samples. These results aligned with previous investigations. ${ }^{41,42}$ Furthermore, serum IL-8 was shown to be higher in OSCC group with a highly significant difference when compared to the healthy controls. That was in accordance with previous studies ${ }^{43-45}$ which firmly showed a significantly elevated IL- 8 levels in serum among subjects having OSCC than control subjects.

Comparing OSCC and OLP groups, this study showed no significant difference in IL-8 levels in saliva, while there was a highly significant difference when comparing each one of the groups to the control group. This was in agreement with former investigations ${ }^{46,47}$ comparing OSCC alone with the healthy control subjects. And, Zhang et al. ${ }^{42}$ who reported similar results comparing OLP, as one of the premalignant lesions, to healthy control subjects. However, other studies ${ }^{36,48,49}$ found highly elevated levels of IL-8 in saliva of OSCC group than oral premalignant and control groups which might be related to the dissimilarity in population and the different number of subjects included in those investigations.

The results of the current investigation advocate that the level of salivary IL -8 may demonstrate the possibility of malignant development in OLP and it may serve as an indicator of diagnosis and/or prognosis of the malignant change of OLP to cancer.

It has been shown that levels of YKL- 40 in serum were increased in various diseases associated with chronic inflammation, ${ }^{50}$ suggesting its pathologic function is related to the process of extracellular matrix remodeling. ${ }^{51}$ This brought attention to the function of YKL-40 in the generation of a variety of human malignancies. For example, YKL-40 expression levels were significantly elevated in ovarian, brain, and breast cancer tissues than levels expressed in nearby normal tissues based on the gene microarray analyses.5. Moreover, a lot of clinical studies have proposed that metastasis and poor prognosis in several human malignancies, such as ovarian, colorectal, breast, brain cancer and leukemia was related to high serum levels of YKL-40 ${ }^{53-57}$ indicating that YKL- 40 levels in the serum might act as a novel biomarker for human malignancies. ${ }^{58}$ 
The present investigation observed that levels of YKL- 40 in the serum was significantly higher in subjects suffering from OSCC compared to both, the OLP group and the healthy controls, this is in accordance with previous reports of an association between elevated levels of YKL- 40 in serum and short survival rate in a variety of human cancers ${ }^{53-57}$ Also salivary YKL-40 levels in saliva were higher than that in the serum in all groups. Salivary YKL40 showed the highest levels in OSCC and OLP with no significant difference between them and both showed a significant difference while compared to the healthy control subjects.

The role of YKL- 40 in malignancy and the tools by which it reveals cancer aggression are not fully recognized. It was proposed that YKL- 40 may take part in cancer cells' differentiation and proliferation, in their protection against apoptosis, in triggering angiogenesis and in tissue remodeling disruption..$^{51}$ However, it has not been elucidated yet which cellular receptors are involved in mediating these effects. ${ }^{59}$

Studies which suggest that YKL-40 might stimulate angiogenesis beside simultaneous elevations in IL-8, could indicate a link between YKL- 40-induced IL- 8 activity and angiogenesis. For instance, kawada et al. 2012, ${ }^{29}$ indicated that YKL-40 induced IL-8 production from colon cancer cells promoted angiogenesis as well as macrophage recruitment. Therefore, YKL-40 appears to have an additional angiogenic action that is independent of VEGF. In addition Chen et al. ${ }^{60}$ indicated that YKL40 can also activate the NF-kB pathway. Moreover, Shao et al. ${ }^{61}$ established that recombinant YKL- 40 has a direct influence on angiogenesis. However, there is a deficiency in investigations linking between YKL-40 and IL-8 in both saliva and serum in the current literature, thus more studies are required to explain the exact function of YKL- 40 in IL-8 generated angiogenesis and if the elevated YKL-40 noted in the current investigation could modulate angiogenesis in OSCC by elevating IL-8 levels.

Guerra et al ${ }^{62}$ in a systematic review, established a conclusion that not many saliva biomarkers used for the initial discovery of oral malignancies were precise. The perfect diagnostic biomarker should be present in all patients with the disease, should show high sensitivity and specificity to disease, and should elicit a cut off point with negligible intersection between illness and normal conditions.

In the present study, in order to discriminate between patients suffering from OSCC and patients having OLP alone, the ROC curve interpretation for serum YKL-40 revealed that the AUC is 0.878 showing high sensitivity (93\%) and specificity $(80 \%)$ levels. This was followed by salivary YKL40 and serum IL- 8 both revealing a good diagnostic accuracy showing an AUC of 0.789 for both with sensitivity (93\% and $80 \%)$ and specificity $(73.3 \%$ and $60 \%$ ) respectively. Salivary IL-8 also showed a good diagnostic accuracy (AUC 0.7) with levels of sensitivity $80 \%$ and specificity $63 \%$. This investigation proposes that the studied biomarkers might serve as diagnostic indicators of malignant change of OLP into OSCC. This is in accordance with other reports showing that the initial angiogenic activity might participate in stimulating cancer development within dysplastic changes of the epithelium. ${ }^{63,64}$

Thus, based on our work we can advocate that salivary YKL-40 and IL-8 could be counted as biomarkers for identifying cancerous changes of OLP and the initial stage of OSCC. The current study offers salivary biomarkers that are sensitive and might be used as a potential non-invasive way for the initial recognition of OSCC.$^{65}$ However, further large-scale investigations needs to be conducted to determine the efficacy of these biomarkers as the identification of initial malignant transformation could be valuable for prompt intervention and a better chance of cure. 


\section{REFERENCES}

1. Gupta S, Jawanda MK. Oral Lichen Planus: An Update on Etiology, Pathogenesis, Clinical Presentation, Diagnosis and Management. Indian J Dermatol. 2015 MayJun;60(3):222-9

2. Irani S, Esfahani AM, Ghorbani A. Dysplastic change rate in cases of oral lichen planus: A retrospective study of 112 cases in an Iranian population. J Oral Maxillofac Pathol. 2016 Sep-Dec; 20(3): 395-399.

3. Fang M, Zhang W, Chen Y, He Z. Malignant transformation of oral lichen planus: A retrospective study of 23 cases. Quintessence Int. 2009; 40:235-42.

4. Vigneswaran N1, Williams MD2. Epidemiologic trends in head and neck cancer and aids in diagnosis. Oral Maxillofac Surg Clin North Am. 2014 May;26(2):123-41.

5. Erreni M, Bianchi P, Laghi L, Mirolo M, Fabbri M, Locati M, Mantovani A, Allavena P. Expression of chemokines and chemokine receptors in human colon cancer. Methods Enzymol. 2009;460:105-21.

6. Coussens LM, Werb Z. Inflammation and cancer. Nature. 2002 Dec 19-26;420(6917):860-7. Review.

7. Aggarwal BB, Shishodia S, Sandur SK, Pandey MK, Sethi G. Inflammation and cancer: how hot is the link? Biochem Pharmacol. 2006 Nov 30;72(11):1605-21.

8. Cha YI, DuBois RN. NSAIDs and cancer prevention: targets downstream of COX-2. Annu Rev Med. 2007;58: 239-52.

9. Waugh DJ and Wilson C. The inerleukin-8 Pathway in Cancer. Clin Cancer Res 2008; 14(21): 6735-41.

10. Kunkel SL, Standiford T, Kasahara K, Strieter RM. Interleukin-8 (IL-8): the major neutrophil chemotactic factor in the lung. Exp Lung Res. 1991 Jan-Feb; 17(1):17-23.

11. Abboud CN, Scully SP, Lichtman AH, Brennan JK, Segel GB. The requirements for ionized calcium and magnesium in lymphocyte proliferation. J Cell Physiol. 1985;122: 64-72.

12. Al-Dalaan A, al-Sedairy S, al-Balaa S, al-Janadi M, Elramahi K, Bahabri S, et al. Enhanced interleukin 8 secretion in circulation of patients with Behçet's disease. J Rheumatol. 1995;22:904-7.

13. Matsushima K1, Morishita K, Yoshimura T, Lavu S, Kobayashi Y, Lew W, Appella E, Kung HF, Leonard EJ, Oppenheim JJ. Molecular cloning of a human monocyte- derived neutrophil chemotactic factor (MDNCF) and the induction of MDNCF mRNA by interleukin 1 and tumor necrosis factor. J Exp Med. 1988 Jun 1;167(6):1883-93.

14. Burke SM1, Issekutz TB, Mohan K, Lee PW, Shmulevitz M, Marshall JS. Human mast cell activation with virusassociated stimuli leads to the selective chemotaxis of natural killer cells by a CXCL8-dependent mechanism. Blood. 2008 Jun 15;111(12):5467-76. doi: 10.1182/ blood-2007-10-118547. Epub 2008 Apr 18.

15. Fredriksson K, Lundahl J, Palmberg L, Romberger DJ, Liu XD, Rennard SI, Skold CM. Red blood cells stimulate human lung fibroblasts to secrete interleukin-8. Inflammation. 2003 Apr;27(2):71-8.

16. Zouboulis CC, Katsantonis J, Ketteler R, Treudler R, Kaklamani E, Hornemann S, et al. Adamantiades-Behçet's disease: Interleukin- 8 is increased in serum of patients with active oral and neurological manifestations and is secreted by small vessel endothelial cells. Arch Dermatol Res. 2000;292:279-84.

17. Yamamoto T, Osaki T. Characteristic cytokines generated by keratinocytes and mononuclear infiltrates in oral lichen planus. J Invest Dermatol. 1995;104:784-8.

18. Sun A, Wang JT, Chia JS, Chiang CP. Serum interleukin-8 level is a more sensitive marker than serum interleukin-6 level in monitoring the disease activity of oral lichen planus. Br J Dermatol. 2005;152:1187-92.

19. De Moura Castro Jacques C, Cardozo Pereira AL, Cabral MG, Cardoso AS, Ramos-e-Silva M. Oral lichen planus part I: Epidemiology, clinics, etiology, immunopathogeny, and diagnosis. Skinmed. 2003;2:342-7.

20. Luca M, Huang S, Gershenwald JE, Singh RK, Reich R, Bar-Eli M. Expression of interleukin-8 by human melanoma cells up-regulates MMP-2 activity and increases tumor growth and metastasis. Am J Pathol. 1997 Oct;151(4):1105-13.

21. Harada K, Supriatno, Yoshida H, Sato M. Vesnarinone inhibits angiogenesis and tumorigenicity of human oral squamous cell carcinoma cells by suppressing the expression of vascular endothelial growth factor and interleukin-8. Int J Oncol. 2005 Dec;27(6):1489-97.

22. Rehli M, Krause SW, Andreesen R. 1997. Molecular characterization of the gene for human cartilage gp-39 (CHI3L1), a member of the chitinase protein family and marker for late stages of macrophage differentiation. Genomics. 43:221-225. 
23. Deming Y, Black K, Carrell D, Cai Y, Del-Aguila JL, Fernandez MV, Budde J, Ma S, Saef B, Howells B, Bertelsen S, Huang KL, Sutphen CL, Tarawneh R, Fagan AM, Holtzman DM, Morris JC, Goate AM, Dougherty JD, Cruchaga C.Chitinaselike 1 protein (CHI3L1) locus influences cerebrospinal fluid levels of YKL-40. BMC Neurol. 2016 Nov 10;16(1):217.

24. Chiang YC, Lin HW, Chang CF, Chang MC, Fu CF, Chen TC, Hsieh SF, Chen CA, Cheng WF Overexpression of CHI3L1 is associated with chemoresistance and poor outcome of epithelial ovariancarcinoma. Oncotarget. 2015 Nov 24;6(37):39740-55. doi: 10.18632/oncotarget.5469.

25. Kazakova MH, Sarafian VS. YKL-40 - a novel biomarker in clinical practice? Folia Med (Plovdiv). 2009;51(1):5-14.

26. Johansen JS, Schultz NA, Jensen BV. Plasma YKL40: a potential new cancer biomarker? Future Oncol. 2009;5(7):1065-82. doi:10.2217/fon.09.66.

27. Kazakova M, Batalov A, Deneva T, Mateva N, Kolarov Z, Sarafian V. Relationship between sonographic parameters and YKL-40 levels in rheumatoid arthritis. Rheumatol Int. 2013;33(2):341-6. doi:10.1007/s00296012-2387-3.

28. Wang D, Zhai B, Hu F, Liu C, Zhao J, Xu J. High YKL-40 serum concentration is correlated with prognosis of Chinese patients with breast cancer. PLoSOne. 2012;7(12):e51127. doi:10.1371/journal.pone.0051127.

29. Kawada M, et al. Chitinase 3-like 1 promotes macrophage recruitment and angiogenesis in colorectal cancer. Oncogene. 2012; 31(26):3111-3123.

30. Tang H, et al. YKL-40 induces IL-8 expression from bronchial epithelium via MAPK (JNK and ERK) and NF-kappaB pathways, causing bronchial smooth muscle proliferation and migration. J Immunol. 2013; 190(1):438-446. [PubMed: 23197259]

31. Abramson JH. The cornell medical index as an epidemiological tool. Am J Public Health Nations Health 1966; 56: 287-298.

32. Yakob M1, Fuentes L1, Wang MB1, Abemayor E1, Wong DT1. Salivary biomarkers for detection of oral squamous cell carcinoma - current state and recent advances. Curr Oral Health Rep. 2014 Jun 1;1(2):133-141.

33. Wang Q, Gao P, Wang X, Duan Y. Investigation and identification of potential biomarkers in human saliva for the early diagnosis of oral squamous cell carcinoma. Clin Chim Acta 2014 427:79-85. Epub 2013/10/23. doi: 10.1016/j.cca.2013.10.004

34. Irani S, Monsef Esfahani A, Bidari Zerehpoush F. Detection of Helicobacter pylori in oral lesions. J Dent Res Dent Clin Dent Prospects. 2013;7:230-7.

35. ChenY, ZhangW, GengN, Tian K, JackWindsor L.MMPs, TIMP-2, and TGF-beta1 in the cancerization of oral lichen planus. Head Neck. 2008 30(9):1237-1245. Epub 2008/07/22. doi: 10.1002/hed.20869. PubMed PMID: 18642282 .

36. Rhodus NL, Ho V, Miller CS, Myers S, Ondrey F. NF$\mathrm{kB}$ dependent cytokine levels in saliva of patients wih oral preneoplastic lesions and oral squamous cell carcinoma. Cancer Detect Prev 2005; 29(1): 42-45.

37. Khan A, Farah CS, Savge NW, Walsh LJ,Harbrow DJ, Sugerman PB. Th1 cytokines in oral lichen planus. J Oral Pathol Med 2003; 32: 77-83.

38. Rao SK, Pavicevic Z, Du Z, Kim JG, Fan M, Jiao Y, Rosebush M, Samant S, Gu W, Pfeffer LM, and Norsat CA. Pri-inflammatory Genes as Biomarkers and Therapeutic Targets in Oral Squamous Cell Carcinoma. J Biol Chem 2010; 285(42): 32512-32521.

39. Veltri RW, Miller MC, Zhao G, Ng A, Marley GM, Wright GL Jr, Vessella RL, Ralph D. Interleukine-8 serum levels in patients with benign prostatic hyperplasia and prostate cancer. Urology 1999; 53: 139-147.

40. Uehara H, Toncoso P, Johnston D, Bucana CD, Dinney C, Dong Z, Fidler IJ, Pettawwway Ca. Expression of interlekine- 8 gene in radical prostatectomy specimens is associated with advanced pathologic stage. Prostate 2005; 64:40-49.

41. St John MA, Li Y, Zhou X, Denny P, Ho CM, Montemagno C, Shi W, Qi F, Wu B, Sinha U, Jordan R, Wolinsky L, Park NH, Liu H, Abemayor E, Wong DT. Interleukin 6 and interleukin 8 as potential biomarkers for oral cavity and oropharyngeal squamous cell carcinoma. Arch Otolaryngol Head Neck Surg. 2004 Aug;130(8):929-35.

42. Zhang Y, Lin M, Zhang S, Wang Z, Jiang L, Shen J, Bai J, Gao F, Zhou M, Chen Q. NF-kappaB-dependent cytokines in saliva and serum from patients with oral lichen planus: a study in an ethnic Chinese population. Cytokine. 2008 Feb;41(2):144-9. doi: 10.1016/j.cyto.2007.11.004. Epub 2008 Jan 25. 
43. Hoffmann TK, Sonkoly E, Homey B, Scheckenbach K, Gwosdz C, Bas M, Chaker A, Schirlau K, Whiteside TL. Aberrant cytokine expression in serum of patients with adenoid cystic carcinoma and squamous cell carcinoma of the head and neck. Head Neck. 2007 May;29(5):472-8.

44. Gokhale AS, Haddad RI, Cavacini LA, Wirth L, Weeks L, Hallar M, Faucher J, Posner MR. Serum concentrations of interleukin-8, vascular endothelial growth factor, and epidermal growth factor receptor in patients with squamous cell cancer of the head and neck. Oral Oncol. 2005 Jan;41(1):70-6.

45. Gu WL, Yang JJ. Expression and clinical significance of serum interleukin-8 level in patients with oral squamous cell carcinoma. Shanghai Kou Qiang Yi Xue (Shanghai journal of stomatology). $2011 \mathrm{Feb}$;20(1):78-81.

46. Arellano-Garcia ME, Hu S, Wang J, Henson B, Zhou H, Chia D, Wong DT. Multiplexed immunobead-based assay for detection of oral cancer protein biomarkers in saliva. Oral Dis. 2008 Nov;14(8):705-12. doi: 10.1111/j.16010825.2008.01488.x.

47. Brinkmann O, Kastratovic DA, Dimitrijevic MV, Konstantinovic VS, Jelovac DB, Antic J, Nesic VS, Markovic SZ, Martinovic ZR, Akin D, Spielmann N, Zhou H, Wong DT. Oral squamous cell carcinoma detection by salivary biomarkers in a Serbian population. Oral Oncol. 2011 Jan;47(1):51-5. doi: 10.1016/j.oraloncology.2010.10.009. Epub 2010 Nov 24.

48. Rhodus NL, Cheng B, Myers S, Miller L, Ho V, Ondrey F. The feasibility of monitoring NF-kappaB associated cytokines: TNF-alpha, IL-1alpha, IL-6, and IL-8 in whole saliva for the malignant transformation of oral lichen planus. Mol Carcinog. 2005 Oct;44(2):77-82.

49. Punyani SR, Sathawane RS. Salivary level of interleukin-8 in oral precancer and oral squamous cell carcinoma. Clin Oral Investig. 2013 Mar; 17(2):517-24 doi: 10.1007/ s00784-012-0723-3. Epub 2012 Apr 18.

50. Sharif M, Granell R, Johansen J, Clarke S, Elson C, Kirwan JR. Serum cartilage oligomeric matrix protein and other biomarker profiles in tibiofemoral and patellofemoral osteoarthritis of the knee. Rheumatology. 2006 May;45(5):522-6. Epub 2005 Nov 30.

51. Johansen JS. Studies on serum YKL-40 as a biomarker in diseases with inflammation, tissue remodelling, fibroses and cancer. Dan Med Bul 2006;53:172-209.

52. Lal A, Lash AE, Altschul SF, Velculescu V, Zhang L, McLendon RE, Marra MA, Prange C, Morin PJ, Polyak
K, Papadopoulos N, Vogelstein B, Kinzler KW, Strausberg RL, Riggins GJ. A public database for gene expression in human cancers. Cancer Res. 1999 Nov 1;59(21):5403-7.

53. Hogdall EV, Johansen JS, Kjaer SK, Price PA, Christensen L, Blaakaer J, Bock JE, Glud E, Høgdall CK. High plasma YKL-40 level in patients with ovarian cancer stage III is related to shorter survival. Oncol Rep 2003;10:1535-8.

54. Cintin C, Johansen JS, Christensen IJ, Price PA, Sorensen S, Nielsen HJ. Serum YKL-40 and colorectal cancer. Brit J Cancer 1999;79:1494-9.

55. Johansen JS, Christensen IJ, Riisbro R, Greenall M, Han C, Price PA, Smith K, Brünner N, Harris AL. High serum YKL-40 levels in patients with primary breast cancer is related to short recurrence free survival. Breast Cancer Res Treat 2003;80:15-21.

56. Pelloski CE, Mahajan A, Maor M, Chang EL, Woo S, Gilbert M, Colman H, Yang H, Ledoux A, Blair H, Passe S, Jenkins RB, Aldape KD. YKL-40 expression is associated with poorer response to radiation and shorter overall survival in glioblastoma. Clin Cancer Res 2005;11:3326-34.

57. Bergmann OJ, Johansen JS, Klausen TW, Mylin AK, Kristensen JS, Kjeldsen E, Johnsen HE. High serum concentration of YKL-40 is associated with short survival in patients with acute myeloid leukemia. Clin Cancer Res. 2005 Dec 15;11(24 Pt 1):8644-52.

58. Faibish M1, Francescone R, Bentley B, Yan W, Shao R. A YKL-40-neutralizing antibody blocks tumor angiogenesis and progression: a potential therapeutic agent in cancers. Mol Cancer Ther. 2011 May;10(5):742-51. doi: 10.1158/1535-7163.MCT-10-0868. Epub 2011 Feb 25.

59. Roslind A, Johansen JS, Christensen IJ, Kiss K, Balslev E, Nielsen DL, Bentzen J, Price PA, Andersen E. High serum levels of YKL-40 in patients with squamous cell carcinoma of the head and neck are associated with short survival. Int J Cancer. 2008 Feb 15;122(4):857-63.

60. Chen CC, Pekow J, Llado V, Kanneganti M, Lau CW, Mizoguchi A, et al. Chitinase 3-like-1 expression in colonic epithelial cells as a potentially novel marker for colitisassociated neoplasia. Am J Pathol. 2011; 179:1494-1503. [PubMed: 21763261]

61. Shao R, Hamel K, Petersen L, Cao QJ, Arenas RB, Bigelow C, Bentley B, Yan W: YKL-40, a secreted glycoprotein, promotes tumor angiogenesis. Oncogene 2009, 28:4456- 4468 
62. Guerra EN, Acevedo AC, Leite AF, Gozal D, Chardin H, De Luca Canto G. Diagnostic capability of salivary biomarkers in the assessment of head and neck cancer: a systematic review and meta-analysis. Oral Oncol 2015 51(9):805-818.

63. Michailidou EZ,Markopoulos AK, Antoniades DZ. Mast cells and angiogenesis in oral malignant and premalignant lesions. Open Dent J. 2008 2:126-32.
64. Mohtasham N, Babakoohi S, Salehinejad J, MontaserKouhsari L, Shakeri MT, Shojaee S, et al. Mast cell density and angiogenesis in oral dysplastic epithelium and low- and high-grade oral squamous cell carcinoma. Acta Odontol Scand 2010 68(5):300-304.

65. Pfaffe T, Cooper-White J, Beyerlein P, Kostner K, Punyadeera C. Diagnostic potential of saliva: current state and future applications. Clin Chem 2011 57(5):675-687. 